\title{
CORRECTION
}

\section{Correction to: Coordination of muscles to control the footpath during over-ground walking in neurologically intact individuals and stroke survivors}

\author{
Shraddha Srivastava ${ }^{1} \cdot$ Pei-Chun Kao ${ }^{2}$ - Darcy S. Reisman ${ }^{3}$ - Jill S. Higginson ${ }^{4} \cdot J^{\prime}$ ho P. Scholz ${ }^{3}$
}

Published online: 24 March 2018

(c) Springer-Verlag GmbH Germany, part of Springer Nature 2018

\section{Correction to: Exp Brain Res (2016) 234:1903-1914}

https://doi.org/10.1007/s00221-016-4593-9

In the original publication of the article, the corrections for the typographical errors in the equations for variance that affects the footpath $\left(V_{\mathrm{ORT}}\right)$ and the total variance $\left(V_{\mathrm{TOT}}\right)$ should be as following:

$$
\begin{aligned}
V_{\mathrm{ORT}} & =\frac{1}{(N \text { steps })} \frac{1}{d} \sum_{i=1}^{N} f_{\mathrm{ORT}^{2}} \\
V_{\mathrm{TOT}} & =\frac{\left(V_{\mathrm{UCM}} \times(n-d)\right)+\left(\mathrm{V}_{\mathrm{ORT}} \times(d)\right)}{(n+d)}
\end{aligned}
$$

The original article can be found online at https://doi.org/10.1007/ s00221-016-4593-9.

Shraddha Srivastava

srivasts@musc.edu

1 Department of Health Sciences and Research, College of Health Professions, Medical University of South Carolina, 77 President Street, Charleston, SC 29425, USA

2 Department of Physical Therapy, University of Massachusetts Lowell, Lowell, MA 01854, USA

3 Department of Physical Therapy, University of Delaware, Newark, DE 19713, USA

4 Department of Mechanical Engineering, University of Delaware, Newark, DE 19713, USA 